\title{
Preparation of cationic surfactant-modified kaolin for enhanced adsorption of hexavalent chromium from aqueous solution
}

\author{
Neway Belachew ${ }^{1}$ (D) Hirpo Hinsene ${ }^{1}$
}

Received: 11 November 2019 / Accepted: 12 December 2019 / Published online: 24 December 2019

(c) The Author(s) 2019

\begin{abstract}
In the current work, we have reported a cationic surfactant-modified Ethiopian kaolin for improved adsorption of $\mathrm{Cr}(\mathrm{VI})$ from aqueous solution. The raw kaolin was modified by treating with CTAB to enhance the adsorption properties. The crystal structure and vibrational analysis of CTAB-kaolin were investigated by Fourier transform infrared spectroscopy (FTIR) and powder X-ray diffraction (p-XRD) techniques. The successful modification of kaolin by CTAB through intercalation and coating was investigated by XRD and FTIR. p-XRD confirms the raw kaolin obtained from Belesa, Tigo kebele is kaolinite mineral. The study has also focused on the application of kaolin-CTAB for adsorption of hexavalent chromium. The percent removal of $\mathrm{Cr}(\mathrm{VI})$ was investigated at different parameters such as $\mathrm{pH}$, contact time, concentration of $\mathrm{Cr}(\mathrm{VI})$ and adsorbent dosage. CTAB-kaolin shows 99\% removal of $\mathrm{Cr}(\mathrm{VI})$ at the adsorption equilibrium (time $=180 \mathrm{~min}, 100 \mathrm{mg} \mathrm{CTAB}-\mathrm{kaolin}$, $10 \mathrm{ppm} / 100 \mathrm{ml}$ ). The Langmuir and Freundlich isotherm models were used to investigate the adsorption process of chromium onto kaolin-CTAB composites. The equilibrium data obeyed Langmuir model than Freundlich, which shows that the adsorption process proceeds through monolayer adsorption and maximum adsorption capacity was found to be $Q_{\mathrm{o}}=22.72 \mathrm{mg} / \mathrm{g}$. The pseudo-second-order kinetics model is found to be well fitted than Pseudo-first-order kinetics, which implies that the adsorption mechanism more favors electrostatic interaction between chromium and kaolin-CTAB composites. In conclusion, CTAB-kaolin was found to be a promising adsorbent for the efficient removal of $\mathrm{Cr}(\mathrm{VI})$ from the aqueous solution.
\end{abstract}

Keywords CTAB $\cdot$ Kaolin $\cdot \mathrm{Cr}(\mathrm{VI}) \cdot$ Adsorption

\section{Introduction}

During the last decades, water pollution was one of the major concerns for the sustainability of life on earth. Toxic effluents discharged without being treated from various industries have taken huge responsibility for the pollution of water bodies. Among the toxic pollutants, chromium is the subject of many types of research and has taken huge attention in the last few years (Yusuff 2019; Pakade et al. 2019). Chromium can be found in stable $\mathrm{Cr}(\mathrm{VI})$ or $\mathrm{Cr}(\mathrm{III})$ oxidation states. More importantly, $\mathrm{Cr}(\mathrm{VI})$ is considered the most toxic

Electronic supplementary material The online version of this article (https://doi.org/10.1007/s13201-019-1121-7) contains supplementary material, which is available to authorized users.

Neway Belachew

neway.du@gmail.com

1 Department of Chemistry, Debre Berhan University, Debre Berhan, Ethiopia form of $\mathrm{Cr}$, which usually exists in association with oxygen as chromate $\left(\mathrm{CrO}_{4}{ }^{2-}\right)$ or dichromate $\left(\mathrm{Cr}_{2} \mathrm{O}_{7}{ }^{2-}\right)$ oxyanions (Sharma and Bhattacharyya 2005). Cr(III) is less toxic and less mobile and is mainly found bound to the organic matter in the aquatic environments and soil (Raji and Anirudhan 1998). The Agency for Toxic Substances and Disease Registry classifies $\mathrm{Cr}(\mathrm{VI})$ as the top 16th hazardous substance due to its severe toxicity (ATSDR 1999). The maximum value of chromium intended for human consumption is estimated as $0.1 \mathrm{mg} \mathrm{L}^{-1}$ (World Health Organization 1993; Duranoğlu et al. 2012). Therefore, the removal of $\mathrm{Cr}(\mathrm{VI})$ from water bodies is of prime importance.

Numerous technologies have been applied for the removal of $\mathrm{Cr}(\mathrm{VI})$ from aqueous solutions such as adsorption (Gupta et al. 2013), reduction (Bhati et al. 2019), ion exchange (Rengaraj et al. 2001) and membrane processes (Zolfaghari and Kargar 2019). The adsorption process is one of the most frequently encountered techniques for the removal of $\mathrm{Cr}(\mathrm{VI})$. Adsorption on activated carbon has been widely used for the removal of a broad range of water pollutants, especially 
for low-to-moderate-concentration pollutants (Pérez-Candela et al. 1995; Demirbas et al. 2004; Khezami and Capart 2005). However, because of the high cost of activated carbon, it is desirable to search for a low-cost and efficient adsorbent for the removal of $\mathrm{Cr}(\mathrm{VI})$ (Belachew and Bekele 2019; Saleem et al. 2019).

In this regard, because of having high cation exchange capacity, swelling capacity, high specific surface area and strong adsorption capacity, clay minerals play an important role in the environment by acting as a natural adsorbent of pollutants (Bhattacharyya and Gupta 2006). Among clay types, kaolin shows the potential for removal of water contaminants (Deng et al. 2014). Kaolinite is the most important mineral component in kaolin, which has received considerable attention as an adsorbent because of its high adsorption capacity, large specific surface area and good physical and chemical stability (Saada et al. 2003). However, the adsorption capacity of raw kaolin is still insufficient for the removal of water pollutants below the recommended level. Hence, modification of kaolinite through intercalation of inorganic and organic compounds has brought additional adsorption efficiency (Duarte-Silva et al. 2014; Zenasni et al. 2014; Diab et al. 2015; Shaban et al. 2018).

In this study, we have reported cetyl trimethyl ammonium bromide (CTAB)-modified kaolinite (CTAB-kaolinite) for efficient adsorption of $\mathrm{Cr}(\mathrm{VI})$ aqueous solution. The adsorption efficiency of CTAB-kaolinite has been investigated at different adsorption parameters such as $\mathrm{pH}$, adsorbent type, adsorbent dose and $\mathrm{Cr}(\mathrm{VI})$ dose. The adsorption kinetics and adsorption isotherm analyses of $\mathrm{Cr}(\mathrm{VI})$ adsorption were also investigated.

\section{Experimental}

\section{Materials}

Natural raw kaolin was obtained from the South Region, Hadiya Zone, Belesa district, Ethiopia. Hydrochloric acid ( $\mathrm{HCl} 36 \%)$, sodium chloride $(\mathrm{NaCl} 60 \%)$, sodium hydroxide $(\mathrm{NaOH} 97 \%)$ potassium dichromate $\left(\mathrm{K}_{2} \mathrm{Cr}_{2} \mathrm{O}_{7}\right)$ and cetyl trimethyl ammonium bromide (CTAB) used for CTAB-kaolin preparation were purchased from Sigma-Aldrich. Analytical-grade $\mathrm{K}_{2} \mathrm{Cr}_{2} \mathrm{O}_{7}$ was purchased from Merck Chemicals. Distilled water was used throughout the whole experiment.

\section{Preparation of CTAB-kaolin}

The raw kaolin sample was washed three times with distilled water to remove surface contaminants and then dried in a ceramic crucible at $105{ }^{\circ} \mathrm{C}$ for $5 \mathrm{~h}$. The dried kaolin sample was crushed to fine particles. The $<2 \mu \mathrm{m}$ fraction of powdered kaolin was collected for further use. For the preparation of CTAB-kaolin, $5 \mathrm{gm}$ of powdered kaolin was added to $250 \mathrm{ml}$ of $5 \mathrm{mmol}, 10 \mathrm{mmol}, 15 \mathrm{mmol}$ and 20 mmol CTAB solutions. The solution was shaken for $5 \mathrm{~h}$ at $70^{\circ} \mathrm{C}$, and then, the CTAB-modified kaolin solution was aged overnight to settle down the CTAB-kaolin. The precipitate was washed at least three times with distilled water until all bromide removed from the solution. The presence of bromide ions is indicated by the formation of the white precipitate by adding $\mathrm{AgNO}_{3}$. The CTAB-kaolin was finally filtered and dried at $105{ }^{\circ} \mathrm{C}$ for $2 \mathrm{~h}$ and gently ground using a mortar and pestle to fine powder particles.

\section{Characterizations}

The UV-visible absorption spectra were recorded using a Shimadzu 2450—SHIMADZU spectrometer. The FTIR spectra of powder samples were recorded in the range of 400-4000 $\mathrm{cm}^{-1}$ using a SHIMADZU-IR PRESTIGE-2 spectrometer by mixing the samples thoroughly with $\mathrm{KBr}$ and pressing them into thin transparent pellets range. $\mathrm{X}$-ray diffraction (XRD) patterns were recorded by PANalytical X'Pert Pro diffractometer at $0.02 \mathrm{deg} / \mathrm{s}$ scan rate using $\mathrm{Cu}-\mathrm{k} \alpha 1$ radiation $(1.5406 \AA, 45 \mathrm{kV}, 40 \mathrm{~mA})$. The morphologies of the samples were characterized using scanning electron microscopy (SEM, JEOL-JSM6610 LV).

\section{Batch adsorption study of chromium(VI)}

All experiments were carried out in batch adsorption mode. In particular, $50 \mathrm{mg}$ of CTAB-kaolin was mixed with $100 \mathrm{ml}$ of $\mathrm{Cr}(\mathrm{VI})$ in 250-ml Erlenmeyer glass flask. The bottles were then stirred at a different predetermined time intervals. Then, $3 \mathrm{ml}$ of the solution was withdrawn and centrifuged (2500 rpm). The $\mathrm{pH}$ was adjusted by $0.1 \mathrm{M} \mathrm{HCl}$ and $0.1 \mathrm{M}$ $\mathrm{NaOH}$. The sample was taken and filtered by the Whatman membrane filter paper of pore size $0.45 \mu \mathrm{m}$ using a syringe. Finally, the absorbance of the residual $\mathrm{Cr}(\mathrm{VI})$ concentration in the solution was determined using UV-Vis spectrophotometer. The adsorption process was optimized at different $\mathrm{pH}$, contact times, $\mathrm{Cr}(\mathrm{VI})$ concentrations and adsorbent doses at room temperature. The removal (\%) and adsorption capacity $(\mathrm{mg} / \mathrm{g})$ of CTAB-kaolin were calculated using Eqs. 1 and 2 respectively:

Removal $(\%)=\left(A_{\mathrm{O}}-A_{t}\right) / A_{\mathrm{O}} * 100$

$q_{\mathrm{t}}=\left(C_{\mathrm{o}}-C_{\mathrm{e}}\right) V / m$

where $A_{\mathrm{O}}$ represents initial absorbance and $A_{t}$ is absorbance of $\mathrm{Cr}(\mathrm{VI})$ at a time $t$. Co denotes the initial $\mathrm{Cr}(\mathrm{VI})$ concentration $(\mathrm{ppm}), C_{\mathrm{e}}$ is the equilibrium $\mathrm{Cr}(\mathrm{VI})$ concentration $(\mathrm{mg} / \mathrm{L})$ in solution after adsorption, $V$ is the volume $(\mathrm{L})$ of the aqueous solution and $\mathrm{m}$ is the mass $(\mathrm{g})$ of CTAB-kaolin. 


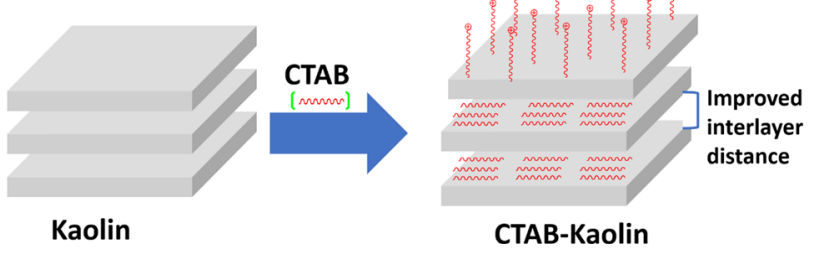

Fig. 1 Schematic diagram of the preparation of CTAB-kaolin

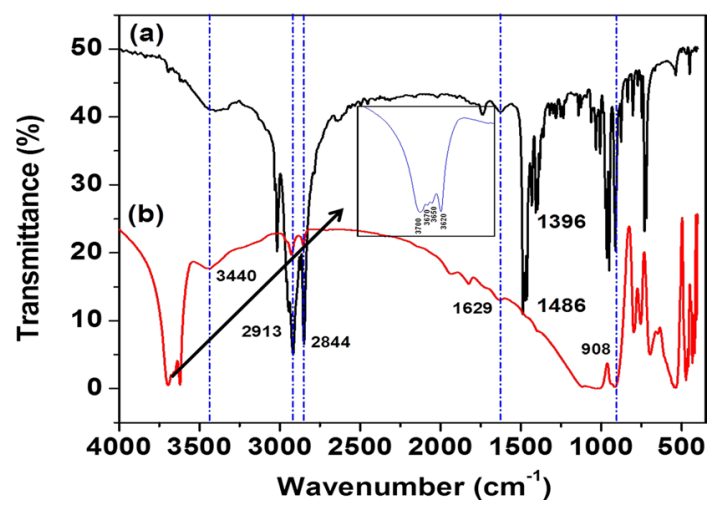

Fig. 2 FTIR spectra of $\mathbf{a}$ CTAB and $\mathbf{b}$ kaolin-CTAB

The point of zero charge of CTAB-kaolin was determined by solid addition method as it is shown in SI.1.

\section{Results and discussions}

\section{Modified kaolin}

The modification was carried out by coating and intercalation into the interlayer spacing of the kaolin using CTAB as shown in Fig. 1. Hence, the surface of kaolin became positively charged. The positive surface charge of CTAB-kaolin is reasonable for the electrostatic interaction between the negative charge species of hexavalent chromium $\left(\mathrm{Cr}_{2} \mathrm{O}_{7}{ }^{-}\right.$and $\mathrm{CrO}_{4}^{-}$). The intercalation of CTAB has also created an additional interlayer surface area for adsorption of $\mathrm{Cr}(\mathrm{VI})$.

\section{Characterization}

\section{FTIR analysis}

Figure 2 shows the FTIR spectra of CTAB and CTAB-kaolin. CTAB and kaolin-CTAB show a band $3444 \mathrm{~cm}^{-1}$, which is due to $\mathrm{O}-\mathrm{H}$ stretching vibrations of adsorbed water. The most intense absorption bands at 2913 and $2844 \mathrm{~cm}^{-1}$ in the spectrum of CTAB are associated with the antisymmetric and symmetric $\mathrm{C}-\mathrm{H}$ stretching vibration modes of the methylene groups (Padalkar et al. 2009). The FTIR spectrum

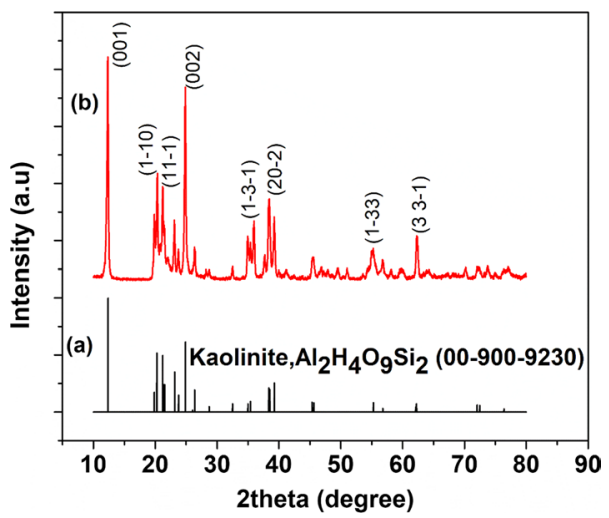

Fig. 3 Powder X-ray diffractogram of a reference kaolinite and $\mathbf{b}$ raw kaolin sample obtained from Hadya, Ethiopia

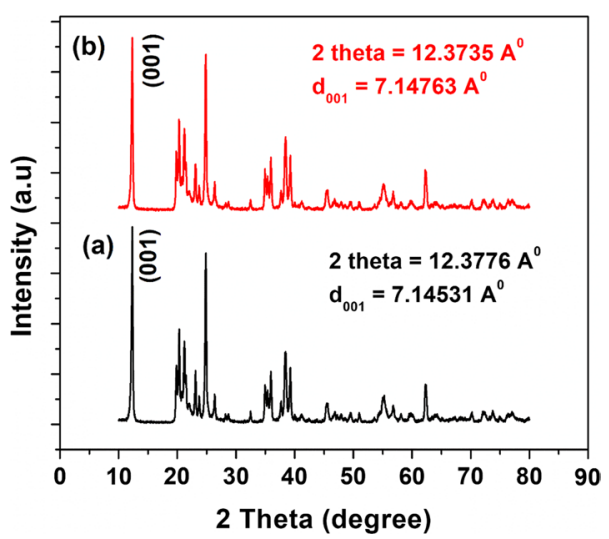

Fig. 4 Powder XRD diffractogram of a pure kaolin and b CTABkaolin

of CTAB-kaolin (Fig. 2a) shows the characteristic absorption bands of kaolinite at $3700,3670,3650$ and $3620 \mathrm{~cm}^{-1}$ due to the inner $\mathrm{OH}$ attached to $\mathrm{Al}$ or $\mathrm{O}$ (Padalkar et al. 2009; Tironi et al. 2012). When the band at $3670 \mathrm{~cm}^{-1}$ disappears, the kaolinite structure is disordered and more easily dehydrated (Padalkar et al. 2009). The stretching peak at $908 \mathrm{~cm}^{-1}$ is ascribed to $\mathrm{Si}-\mathrm{O}$ or $\mathrm{Si}-\mathrm{O}-\mathrm{Al}$ (Nakamoto 1986).

\section{XRD and SEM analysis}

The kaolin structure before and after modification by CTAB was further investigated by powder XRD. Figure 3 shows the XRD pattern of raw Ethiopian kaolin. The raw kaolin was indexed to the diffraction pattern of crystalline-layered kaolinite, which is matched with COD card number 00-9009230 (Bish 1989). The peaks at $12.3^{\circ}, 20,32^{\circ}, 21.22^{\circ}, 23.1^{\circ}$, $24.86^{\circ}, 35.96^{\circ}, 38.48^{\circ}$ and $55.2^{\circ}$ can be indexed to the plane due to kaolinite (001), (11̄0), (11 $\overline{1}),(002),(1 \overline{3} \overline{1}),(20 \overline{2})$ and (133), respectively. As shown in Fig. 4, the characteristic (001) diffraction peak of kaolinite shifts from $12.2776^{\circ}$ to 
$12.3735^{\circ}$ after treatment by CTAB, which ascribes the intercalation of CTAB to kaolin layer. The d-spacing of kaolinite at (001) shows expansion from 7.14531 to $7.14763 \AA$, which is shown to be further strengthening the intercalation of CTAB. The surface morphology of CTAB-kaolin was investigated using SEM. CTAB-kaolin shows porous surface morphology (Figure S1), which is suitable for adsorption purpose.

\section{Adsorption study}

\section{Point of zero charge $\left(\mathrm{pH}_{\mathrm{PZC}}\right)$ and effect of $\mathrm{pH}$}

The $\mathrm{pH}_{\mathrm{PZC}}$ is the $\mathrm{pH}$ at which the adsorbent has a neutral charge on the surface. The $\mathrm{pH}_{\mathrm{PZC}}$ of the adsorbent was determined by using the solid addition method (Balistrieri and Murray 1981; Zubrik et al. 2017). The $\mathrm{pH}_{\mathrm{PZC}}$ for the CTAB-kaolin was found to be 6.2 (Fig. 5). Hence, when the $\mathrm{pH}$ of solution is less than $\mathrm{pH}_{\mathrm{PZC}}$, the CTAB-kaolin surface becomes positive and attracts anions (such as $\mathrm{CrO}_{4}{ }^{2-}$ ) from the aqueous solution, and when it is greater than $\mathrm{pH}_{\mathrm{PZC}}$, the surface becomes negative and attracts cations from the solution.

Figure 6 shows the $\mathrm{Cr}(\mathrm{VI})$ removal (\%) efficiency of $\mathrm{CTAB}-\mathrm{kaolin}$ as a function of $\mathrm{pH}$. The maximum removal (\%) of hexavalent chromium is higher at low $\mathrm{pH} 2$. As the $\mathrm{pH}$ increases, the surface of kaolin becomes more negatively charged, which reasonably increases the repulsion between $\mathrm{CrO}_{4}{ }^{2-}[\mathrm{Cr}(\mathrm{VI})]$ and kaolin-CTAB. Hence, the removal efficiency decreases with an increase in $\mathrm{pH}$.

\section{Effect of adsorbent type and contact time}

The effect of CTAB on the adsorption efficiency of kaolin was examined (Figure S2). CTAB-kaolin showed superior adsorption efficiency than pure kaolin, which is due to the enhanced electrostatic interaction of $\mathrm{Cr}_{2} \mathrm{O}_{7}{ }^{-} / \mathrm{CrO}_{4}{ }^{-}$with an adsorbed cationic surfactant, CTAB.

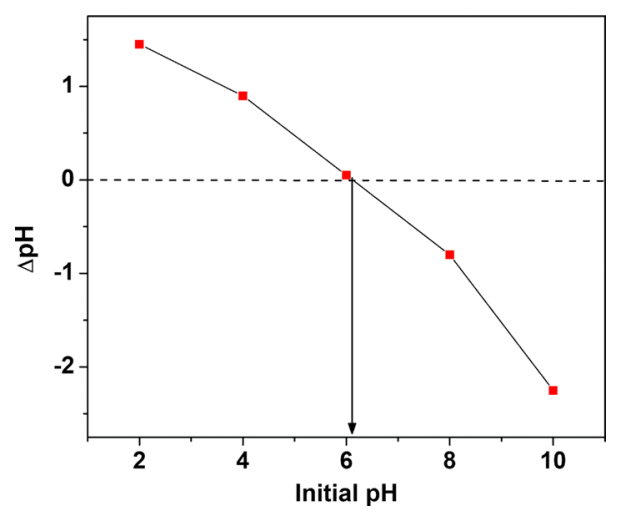

Fig. 5 Point of zero charge analysis of CTAB-kaolin

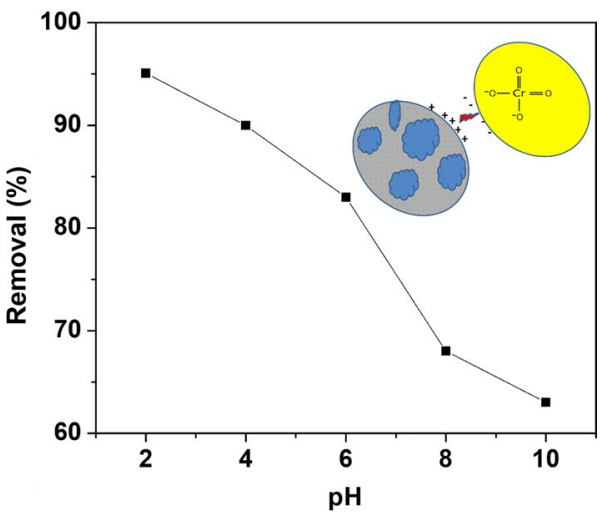

Fig. 6 Effect of $\mathrm{pH}$ on the adsorption removal efficiency of CTABkaolin (inset: the plausible electrostatic adsorption mechanism between $\mathrm{CTAB}$-kaolin and $\mathrm{CrO}_{4}^{-}$)

Figure 7 shows the effect of time on adsorption. The adsorption process was completed within $180 \mathrm{~min}$ where total surface coverage of CTAB-kaolin was completed and no further adsorption was observed. Hence, the adsorption within 180 min contact time could be considered as adsorption equilibrium. The adsorption removal of chromium is increased upon the increasing contact time and 95\% removal efficiency (50 mg CTAB-kaolin and 5 ppm $\mathrm{Cr}$ (VI) solution). The fast adsorption rate of $\mathrm{Cr}(\mathrm{VI})$ was observed in the first $90 \mathrm{~min}$.

\section{Effect of initial concentration}

The effect of initial concentration of $\mathrm{Cr}(\mathrm{VI})$ is shown in Fig. 7. Initial concentration was varied from 5 to $20 \mathrm{ppm}$. Results show that the removal (\%) decreases as the initial concentration of hexavalent chromium increased. This implies the adsorption of $\mathrm{Cr}$ (VI) onto kaolin-CTAB is strongly dependent on initial metal ion concentration. At low initial hexavalent chromium concentrations, the available

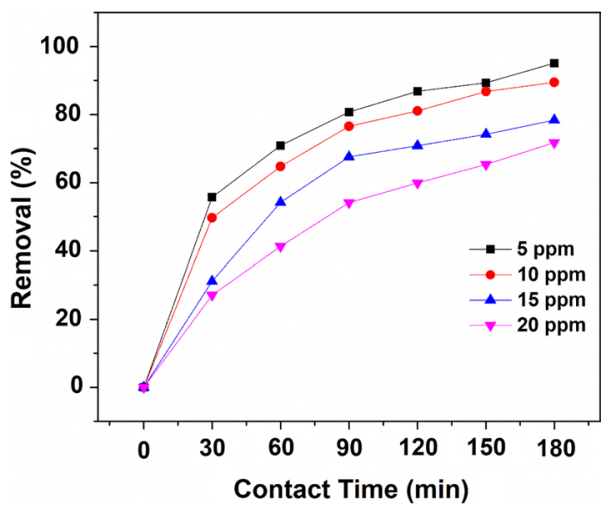

Fig. 7 Effect of initial concentration on $\mathrm{Cr}(\mathrm{VI})$ on the adsorption efficiency of CTAB-kaolin (50 mg) 
adsorption sites were easily occupied by hexavalent chromium resulting in higher removal efficiencies. However, as the initial concentration of hexavalent chromium increased, most of the available adsorption sites became occupied, leading to a decrease in the removal efficiency. The minimum and maximum removal efficiencies were found to be $69 \%$ and $95.08 \%$ for $20 \mathrm{ppm}$ and $5 \mathrm{ppm}$ solution, respectively.

\section{Adsorbent dose}

The adsorbent dose is an important parameter in adsorption studies because it determines the capacity of adsorbent for a given initial concentration of a metal ion in the solution. The adsorption removal (\%) of $\mathrm{Cr}(\mathrm{VI})$ at different doses of CTAB-kaolin is depicted in Fig. 8. The removal of $\mathrm{Cr}(\mathrm{VI})$ increases with an increase in CTAB-kaolin dose. The results showed that $99 \%$ removal efficiency was achieved using $100 \mathrm{mg}$ CTAB-kaolin for $10 \mathrm{ppm} \mathrm{Cr}(\mathrm{VI})$ in a $100 \mathrm{ml}$ solution.

\section{Adsorption isotherm}

The adsorption isotherms are used to estimate the maximum adsorption efficiency $\left(q_{\mathrm{o}}\right)$ of CTAB-kaolin at the adsorption equilibrium time. The adsorption isotherm curves of $\mathrm{Cr}(\mathrm{VI})$ on CTAB-kaolin are depicted in Figs. 9 and 10. The adsorption of $\mathrm{Cr}(\mathrm{VI})$ onto the surface of CTAB-kaolin was validated using Langmuir (Langmuir 1916) and Freundlich (Freundlich 1907) models. The linear line form of Langmuir and Freundlich equations is shown in Eqs. 3 and 4, respectively:

$C_{\mathrm{e}} / q_{\mathrm{e}}=1 / Q_{\mathrm{o}} \cdot b_{\mathrm{L}}+C_{\mathrm{e}} / Q_{\mathrm{o}}$

where $q_{\mathrm{e}}(\mathrm{mg} / \mathrm{g})$ is the equilibrium amount of $\mathrm{Cr}(\mathrm{VI})$ adsorption, $Q_{0}(\mathrm{mg} / \mathrm{g})$ refers to the maximum adsorption capacity and $b_{\mathrm{L}}(\mathrm{L} / \mathrm{mg})$ is the Langmuir equilibrium constant related to the enthalpy of the process.

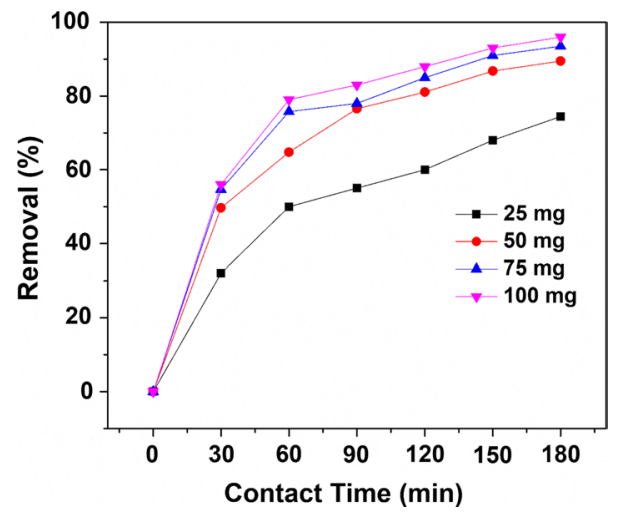

Fig. 8 Effect of adsorbent dose on $\mathrm{Cr}(\mathrm{VI})(10 \mathrm{ppm})$ adsorption

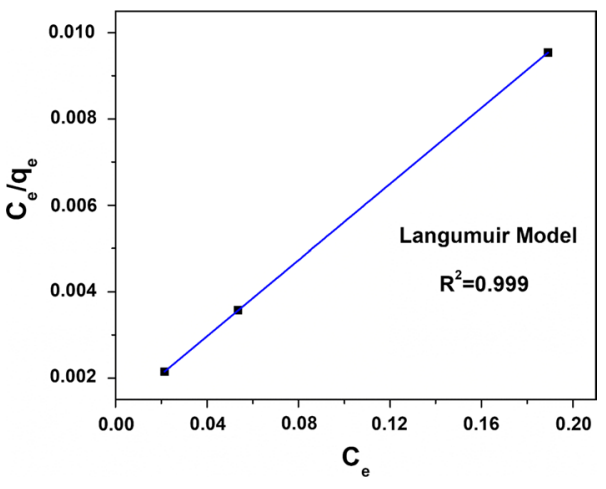

Fig. 9 Langmuir adsorption isotherm curve of $\mathrm{Cr}(\mathrm{VI})$ adsorption on CTAB-kaolin

$\log q_{\mathrm{e}}=\log K_{\mathrm{f}}+(1 / n) * \log C_{\mathrm{e}}$

$K_{\mathrm{F}}(\mathrm{mg} / \mathrm{g})$ is Freundlich constant representing the adsorption capacity at a unit equilibrium concentration that is defined as the adsorption or distribution coefficient, and $1 / n$ is related to the adsorption intensity. The value of ' $n$ ' greater than 1.0 indicates that $\mathrm{Cr}(\mathrm{VI})$ shows favorable adsorption on CTAB-kaolin.

The correlation coefficient $\left(R^{2}\right)$ of the Langmuir adsorption isotherms curve is 0.999 (Table 1), which showed that the adsorption process is well fitted to the Langmuir model than the Freundlich model $\left(R^{2}=0.943\right)$. Therefore, the sorption of $\mathrm{Cr}(\mathrm{VI})$ onto the activated CTAB-kaolin took place predominantly through monolayer adsorption. The maximum monolayer adsorption capacity was theoretically calculated to be $22.72 \mathrm{mg} / \mathrm{g}$. As shown in Table 1 , the value of $R_{\mathrm{L}}$ was between zero and one; as the result indicates, the adsorption process is favorable.

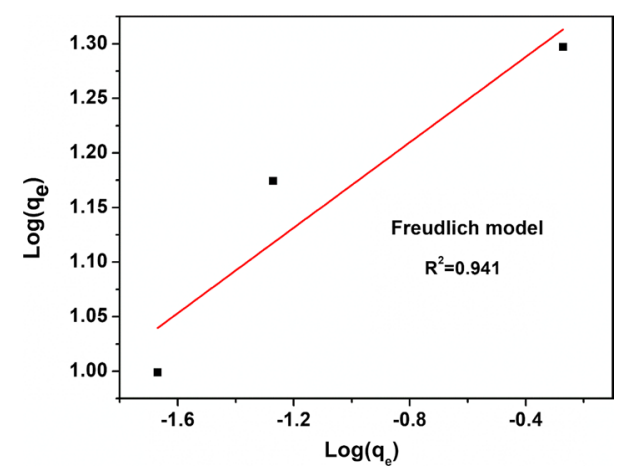

Fig. 10 Freundlich adsorption curve of $\mathrm{Cr}(\mathrm{VI})$ adsorption on CTABkaolin 
Table 1 Langmuir and Freundlich adsorption isotherm parameters

\begin{tabular}{llllll}
\hline Isotherm models & Parameters & & & \\
\cline { 2 - 6 } & $Q_{\mathrm{o}}(\mathrm{mg} / \mathrm{g}$ & $q_{\mathrm{e}(\exp )}$ & $q_{\mathrm{e}(\mathrm{cal})}$ & $b_{\mathrm{L}}$ & 36.77 \\
\hline Langmuir isotherm & 22.72 & 19.82 & 19.859 & $R^{2}$ & 0.9999 \\
\hline Freundlich isotherm & $N$ & $1 / n$ & $k_{\mathrm{f}}\left(\mathrm{mg}^{1-1 / n} \mathrm{~L}^{1 / n} \mathrm{~g}^{-1}\right)$ & $R^{2}$ \\
\hline & 6.6 & 0.151 & 23.3 & 16.78 \\
\hline
\end{tabular}

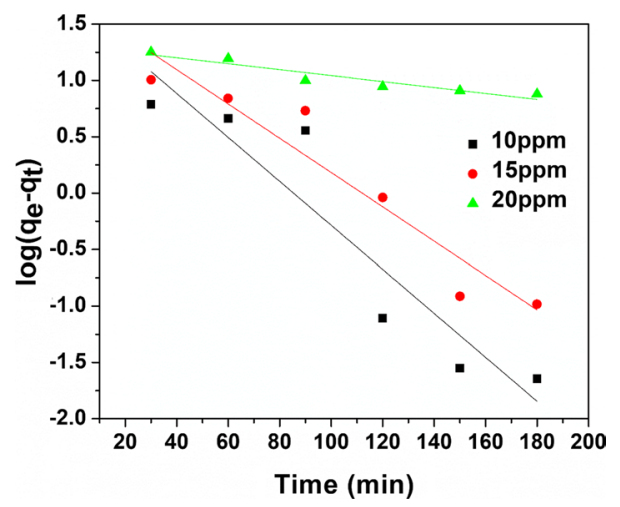

Fig. 11 Pseudo-first-order kinetic curve of $\mathrm{Cr}(\mathrm{VI})$ adsorption onto CTAB-kaolin

\section{Adsorption kinetics}

The adsorption kinetics of $\mathrm{Cr}(\mathrm{VI})$ onto CTAB-kaolin was investigated using Lagergren pseudo-first-order equation (Eq. 5) and pseudo-second-order equation (Eq. 6) models. The Lagergren pseudo-first-order equation is used to express fast adsorption of adsorbate from solution and the process dominantly controlled by diffusion (Lagergren and Vetenskapsakademiens 1898).

$\log \left(q_{\mathrm{e}}-q_{\mathrm{t}}\right)=\log q_{\mathrm{e}}-\left(K_{1} / 2.303\right) * t$

where $k_{1}$ is the pseudo-first-order rate constants of and $q_{\mathrm{e}}$ denotes the equilibrium amount of $\mathrm{Cr}(\mathrm{VI})$ adsorption. The pseudo-second-order kinetic model is based on chemisorption as the rate-determining step, and it implies that adsorption occurs through the electrostatic interaction between adsorbate and adsorbent (Ho 1995).

$t / q_{\mathrm{t}}=1 / K_{2} q_{\mathrm{e}}^{2}+\left(1 / q_{\mathrm{e}}\right) * t$

where $k_{2}$ is pseudo-second-order kinetic models.

The adsorption kinetics evaluated by the two models is presented in Fig. 11 (pseudo-first) and Fig. 12 (pseudosecond). The results showed that the adsorption of $\mathrm{Cr}(\mathrm{VI})$ onto CTAB-kaolin is well fitted to the pseudo-secondorder model $\left(R^{2}>0.99\right)$ than the pseudo-first-order model $\left(R^{2}<0.9\right)$ and the rate-limiting step could be controlled

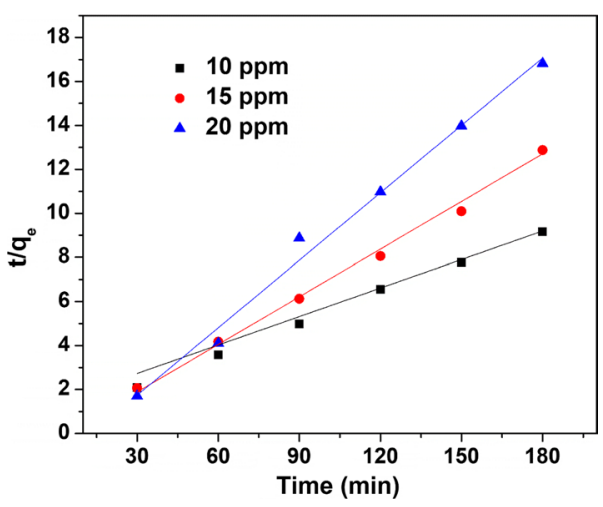

Fig. 12 Pseudo-second-order kinetic curve of $\mathrm{Cr}(\mathrm{VI})$ adsorption onto CTAB-kaolin

Table 2 Pseudo-first- and second-order kinetic parameters

\begin{tabular}{lccc}
\hline Parameters & \multicolumn{3}{c}{ Initial concentration of chromium } \\
\cline { 2 - 4 } & $10 \mathrm{ppm}$ & $15 \mathrm{ppm}$ & $20 \mathrm{ppm}$ \\
\hline Pseudo-first-order kinetics & & \\
$q_{\mathrm{e}}, \mathrm{exp}(\mathrm{mg} / \mathrm{g})$ & 9.9786 & 14.99 & 19.82 \\
$q_{\mathrm{e}}, \mathrm{cal}(\mathrm{mg} / \mathrm{g})$ & 20.23 & 50.11 & 46.02 \\
$k_{1}\left(\mathrm{~min}^{-1}\right)$ & 0.014 & 0.047 & 0.0034 \\
$R^{2}$ & 0.794 & 0.797 & 0.895 \\
Pseudo-second-order kinetics & & \\
$k_{1}\left(\mathrm{~min}^{-1}\right)$ & 0.002 & 0.0581 & 00018 \\
$\left.q_{\mathrm{e}}, \mathrm{cal}^{2} \mathrm{mg} / \mathrm{g}\right)$ & 9.998 & 15.04 & 19.859 \\
$R^{2}$ & 0.992 & 0.997 & 0.989 \\
\hline
\end{tabular}

by the electrostatic interaction between CTAB-kaolin and $\mathrm{Cr}(\mathrm{VI})$. As shown in Table 2, the maximum adsorption efficiency of CTAB-kaolin from pseudo-second-order kinetics $\left(q_{\mathrm{cal}}=19.859\right)$ was found to be in good agreement with experimental $\left(q_{\exp }=19.82\right)$.

\section{Conclusion}

In conclusion, we have successfully prepared and characterized CTAB-intercalated kaolin for improved adsorption of chromium(VI). FTIR and XRD analyses affirm the kaolin 
modification through intercalation and surface coating using CTAB. The adsorption removal $\mathrm{Cr}(\mathrm{VI})$ using CTAB-kaolin was found to be strongly dependent on $\mathrm{pH}$, initial $\mathrm{Cr}(\mathrm{VI})$ concentration and adsorbent dose. The acidic $\mathrm{pH}$ is suitable for uptake of $\mathrm{Cr}(\mathrm{VI})$ by CTAB-kaolin. The monolayer adsorption process is suggested based on the best fitted Langmuir model. 99\% removal $(100 \mathrm{mg}, 10 \mathrm{ppm} / 100 \mathrm{ml})$ and $22.72 \mathrm{mg} / \mathrm{g}$ maximum adsorption efficiency were achieved by CTAB-kaolin. The kinetic study reveals that the pseudo-second-order expresses well the adsorption process than pseudo-first-order model, which attributes to the chemisorption is the rate-determining step. Hence, it is inferred that CTAB-kaolin was found to promising for efficient removal $\mathrm{Cr}(\mathrm{VI})$ from the aqueous solution, especially at low concentrations of $\mathrm{Cr}(\mathrm{VI})$.

Acknowledgements The authors are kindly acknowledging the Debre Berhan University (Chemistry Department) and Ministry of Education of Ethiopia for supporting the work.

Funding The chemical and characterization cost of the research work was covered by Debre Berhan University and Ministry of Education of Ethiopia under the regular fund for graduated students.

\section{Compliance with ethical standards}

Conflict of interest The authors declare that there is no conflict of interest.

Open Access This article is licensed under a Creative Commons Attribution 4.0 International License, which permits use, sharing, adaptation, distribution and reproduction in any medium or format, as long as you give appropriate credit to the original author(s) and the source, provide a link to the Creative Commons licence, and indicate if changes were made. The images or other third party material in this article are included in the article's Creative Commons licence, unless indicated otherwise in a credit line to the material. If material is not included in the article's Creative Commons licence and your intended use is not permitted by statutory regulation or exceeds the permitted use, you will need to obtain permission directly from the copyright holder. To view a copy of this licence, visit http://creativecommons.org/licenses/by/4.0/.

\section{References}

ATSDR (1999) Agency for toxic substances and disease registry toxicological profile information. Toxicol Ind Health 15:743-746

Balistrieri LS, Murray JW (1981) The surface chemistry of goethite (alpha $\mathrm{FeOOH}$ ) in major ion seawater. Am J Sci 281:788-806

Belachew N, Bekele G (2019) Synergy of magnetite intercalated bentonite for enhanced adsorption of Congo red dye. Silicon. https://doi. org/10.1007/s12633-019-00152-2

Bhati A, Anand SR, Saini D et al (2019) Sunlight-induced photoreduction of $\mathrm{Cr}(\mathrm{VI})$ to $\mathrm{Cr}(\mathrm{III})$ in wastewater by nitrogen-phosphorus-doped carbon dots. npj Clean Water 2:12

Bhattacharyya KG, Gupta SS (2006) Adsorption of chromium(VI) from water by clays. Ind Eng Chem Res 45:7232-7240

Bish DL (1989) Rietveld refinement of non-hydrogen atomic positions in kaolinite. Clays Clay Miner 37:289-296

Demirbas E, Kobya M, Senturk E, Ozkan T (2004) Adsorption kinetics for the removal of chromium(VI) from aqueous solutions on the activated carbons prepared from agricultural wastes. Water SA 30:533-539

Deng L, Shi Z, Luo L et al (2014) Adsorption of hexavalent chromium onto kaolin clay based adsorbent. J Cent South Univ 21:3918-3926

Diab AD et al (2015) Comparison between adsorption of copper ions by kaolinite and kaolinite composite. J Soil Water Sci 2:1-8

Duarte-Silva R, Villa-García MA, Rendueles M, Díaz M (2014) Structural, textural and protein adsorption properties of kaolinite and surface modified kaolinite adsorbents. Appl Clay Sci 90:73-80

Duranoğlu D, Kaya İGB, Beker U, Şenkal BF (2012) Synthesis and adsorption properties of polymeric and polymer-based hybrid adsorbent for hexavalent chromium removal. Chem Eng J 181-182:103-112

Freundlich H (1907) Über die adsorption in lösungen. Z Phys Chem $57: 385-470$

Gupta VK, Pathania D, Agarwal S, Sharma S (2013) Removal of Cr(VI) onto Ficus carica biosorbent from water. Environ Sci Pollut Res Int 20:2632-2644

Ho YS (1995) Adsorption of heavy metals from waste streams by peat. $\mathrm{Ph}$.D. Thesis, University of Birmingham, Birmingham, UK

Khezami L, Capart R (2005) Removal of chromium(VI) from aqueous solution by activated carbons: kinetic and equilibrium studies. J Hazard Mater 123:223-231

Lagergren S, Vetenskapsakademiens KS (1898) Zur theorie der sogenannten adsorption gelster stoffe. Handlingar 24:1-39

Langmuir I (1916) The constitution and fundamental properties of solids and liquids. Part I. Solids. J Am Chem Soc 38:2221-2295

Nakamoto K (1986) Infrared and Raman spectra of inorganic and coordination compounds. Wiley, Hoboken

Padalkar KV, Gaikar VG, Aswal VK (2009) Characterization of mixed micelles of sodium cumene sulfonate with sodium dodecyl sulfate and cetyl trimethylammonium bromide by SANS, FTIR spectroscopy and NMR spectroscopy. J Mol Liq 144:40-49

Pakade VE, Tavengwa NT, Madikizela LM (2019) Recent advances in hexavalent chromium removal from aqueous solutions by adsorptive methods. RSC Adv 9:26142-26164

Pérez-Candela M, Martín-Martínez J, Torregrosa-Maciá R (1995) Chromium(VI) removal with activated carbons. Water Res 29:2174-2180

Raji C, Anirudhan TS (1998) Batch Cr(VI) removal by polyacrylamide-grafted sawdust: kinetics and thermodynamics. Water Res 32:3772-3780

Rengaraj S, Yeon KH, Moon SH (2001) Removal of chromium from water and wastewater by ion exchange resins. J Hazard Mater 87:273-287

Saada A, Breeze D, Crouzet C et al (2003) Adsorption of arsenic(V) on kaolinite and on kaolinite-humic acid complexes. Chemosphere 51:757-763

Saleem J, Shahid UB, Hijab M et al (2019) Production and applications of activated carbons as adsorbents from olive stones. Biomass Convers Biorefin 9:775-802

Shaban M, Sayed MI, Shahien MG et al (2018) Adsorption behavior of inorganic- and organic-modified kaolinite for Congo red dye from water, kinetic modeling, and equilibrium studies. J Sol Gel Sci Technol 87:427-441

Sharma A, Bhattacharyya KG (2005) Adsorption of chromium(VI) on Azadirachta indica (Neem) leaf powder. Adsorption 10:327-338

Tironi A, Trezza MA, Irassar EF, Scian AN (2012) Thermal treatment of kaolin: effect on the pozzolanic activity. Procedia Mater Sci $1: 343-350$

World Health Organization (1993) Guidelines for drinking-water quality. World Health Organization, Geneva

Yusuff AS (2019) Adsorption of hexavalent chromium from aqueous solution by Leucaena leucocephala seed pod activated carbon: equilibrium, kinetic and thermodynamic studies. Arab J Basic Appl Sci 26:89-102

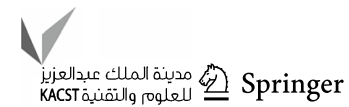


Zenasni MA, Meroufel B, Merlin A, George B (2014) Adsorption of Congo red from aqueous solution using CTAB-kaolin from Bechar Algeria. J Surf Eng Mater Adv Technol 04:332-341

Zolfaghari G, Kargar M (2019) Nanofiltration and microfiltration for the removal of chromium, total dissolved solids, and sulfate from water. MethodsX 6:549-557

Zubrik A, Matik M, Hredzák S et al (2017) Preparation of chemically activated carbon from waste biomass by single-stage and two-stage pyrolysis. J Clean Prod 143:643-653
Publisher's Note Springer Nature remains neutral with regard to jurisdictional claims in published maps and institutional affiliations. 